\title{
Learning with IT: towards a research agenda - questions and issues
}

\author{
Ursula Howard \\ Further Education Development Agency \\ email: uhoward@feda.ac.uk
}

Learning with information technology (IT) is at the top of the research agenda for further and higher education. It is also at the centre of many post-16 investments and policy initiatives. The widespread use in recent years of the term information and learning technology' (ILT) in further education (FE) colleges illustrates the particular focus in that sector. This paper analyses why this conjunction of learning and technology is seen as so important and describes how it has been articulated in practice. It outlines the scope of related research and how this matches the political and social imperatives, the professional development concerns of staff in the sector, and the ever-changing technological context. In its summary of the pertinent research questions, the paper shows how research priorities can be and are being matched by concrete developmental practice.

\section{Introduction}

Rather like the pencil - whose departure was predicted in 1938 by the New York Times in the face of ever more sophisticated typewriters - the fax, the copier and paper documents refuse to be dismissed. People find them useful. Paper has wonderful properties - properties that lie beyond information, helping people work, communicate and think together.

Historians have long argued that the story of the industrial revolution cannot be told by looking at the train alone. Historians might as well whistle for all the effect they have had. The myth of the train is far more powerful. Today it's the myth of information that is overpowering richer explanations (of) the changes society is experiencing.

(Brown and Duiguid, 2000) 
If we make the wrong technological choices, the e-university will be obsolete in the next decade. If we make the wrong curriculum choices, we will end up spending massive sums to deliver learning materials to a very few students. If we adopt the wrong pedagogic approach students will drop out and fail in large numbers.

(O’Shea, 2000)

For many of our students who have extended histories of educational failure IT has the potential to transform the learning process by responding more effectively to individual learning styles.

(NLN, May 2000)

In a recent Further Education Development Agency (FEDA) consultation with colleges, learning with IT was re-confirmed as one of the two top priority research issues in the FE sector along with research into 'effective teaching and successful learning'. The latter might well be associated with concerns about the new post-16 inspection framework, which has far greater emphasis on direct observation of teaching and learning than the outgoing inspection regimes. Nevertheless, there are strong signals that leaders of colleges and other providers of learning opportunities are focused more on learners, quality and curriculum delivery than five years ago.

The expressed need for research into learning with IT exemplifies the core purposes for all educational research: to extend and deepen our knowledge and assemble evidence to address and support change in the learning environment, and to inform and influence policy development. Often enough, a research issue does not emerge within a static or stable context. Education, and particularly post-16 education, has been in a state of permanent change for the last decade. At the present time, the structural arrangements for the funding and planning of all post-16 learning outside $F E$ are being radically reformed, shaped by the Learning and Skills Act 2000. Curricula and qualifications are being reformed: Curriculum 2000 substantially broadens the shape of study for 16-19-year-olds. GNVQs are being transformed into Vocational GCSEs and Vocational A levels, leading, within the general direction of policy, to new Foundation Degrees. In work-based learning, Modern Apprenticeships are being restructured. The overall number of qualifications is to be substantially reduced. A new overarching certificate, 'graduation', is being explored through which it is hoped everyone can achieve FE level 2 by age 19. A new Key Skills qualification is to be introduced in 2000-1 as an essential component of both academic and vocational programmes. At the same time, a major new drive is under way to reach the seven million adults who have problems with reading, writing and numeracy and improve the opportunities available to them. IT is central to all these changes to the post-16 learning system. It is one of the designated key skills, part of the delivery of the curriculum, and increasingly central to the overall shape, structure and provision of learning opportunities.

\section{Change and the influence of IT}

In terms of the pace of change, IT would appear to be the fastest moving research target of all. Tim O'Shea has argued that the technology itself does not move that fast (O'Shea, 2000). To managers and teachers, however, it feels fast enough to cause anxiety. For example, IT is a major focus of investment, and a recurring issue for speedy decisiontaking; consequently managers can fear making the wrong decisions. The universal 
introduction and widespread effects of new technologies appear to demand instant culture change. For example, they raise questions about the nature of institutions and the way they offer learning. FE colleges have traditionally served local communities; in the technological world, with all its possibilities for instant global communication, the notion of 'localness' is exploded and needs to be refocused in new possibilities of community. At worst, there are fears that 'colleges with walls' will be redundant in a dystopian world in which individuals commune one-to-one with technology.

It follows that, in a fast-changing world that is full of uncertainties, quick and practical pieces of research (coupled with the dissemination of good practice, innovation and curriculum development) are needed. These can help educators to investigate, validate and then embed IT-based learning, inform management decisions, and help teachers to work differently, adapting their skills and learning new ones to use and apply IT to support effective learning. In some ideal world, all teachers, tutors and guidance professionals and all curriculum specialists could be versed in the latest technological developments. They would understand how to apply the technology in support of every learner's goals. They could automatically integrate their technological and pedagogic knowledge to create the right learning mix, coupled with the right technology mix for any student.

However, we have a long way to go before this becomes a reality. Despite the excellent practice in some colleges, adult and work-based learning centres, the new post- 16 sector is far from ready for the large-scale adoption of electronic delivery methods. Providers need support to develop and improve their skills and knowledge of how IT can best support learning. At the same time the current national picture contains a plethora of policy initiatives and the potential for overlap and confusion in the minds of professionals and users. While substantial new resources (for example IT-based learning centres in neighbourhoods, Learndirect centres, and a new National Learning Network for FE) are entirely welcome and much needed developments, coherence and connectivity between the mushrooming initiatives and the people running and using them should be high priorities. Simply investing in millions of additional computers is, of itself, not the solution. The reality is, rightly, more complicated and not susceptible to simplistic technological fixes.

\section{The reality for IT research in FE}

Recent and current research, development activity and policy initiatives reveal needs on a large scale, and high levels of interest and commitment to research in IT. These activities also reveal how much still needs to be achieved and the need for coherence in both developing and investing in IT-based learning.

Evidence of both the interest in, and potential for, IT research in FE is demonstrated by recent initiatives such as the curriculum and staff development activities on FEDA's QUILT programme (1996-2001), and the surveys and consultations on which the programme has been based. The QUILT programme revealed the extent of development and support needs in the sector. The Further Education Resources for Learning (FERL) programme, managed by Becta, has successfully shared good practice, for example by including case studies illustrating pockets of excellent practice in its Website. The use of this Website by college staff also illustrates the widespread need for information and useable resources. 
At the same time, the new National Learning Network (NLN) initiative in FE has recognized the importance of staff development in applying IT to learning and the value of nurturing innovation in the curriculum to exploit fully what IT can offer. An initial survey by Becta, which informed the NLN plan, revealed the state of existing technology in colleges upon which developments must build and which itself must be enhanced.

The DfEE is to commission a major piece of research on information and communications technology (ICT) and learning and is setting up a research centre to work on the application of IT to learning. Work is under way to apply the Further Education National Training Organization (FENTO) standards to the use of ICT in teaching and learning. This will be essential to create a systematic, 'learning-centred' approach to developing staff skills and improving the quality of the learning experience. The creation of the University for Industry (UfT) and its focus on direct access and screen-based learning acknowledges the potential of ILT to engage more learners quickly, particularly in work-based settings, and to reach new groups of learners who have not traditionally participated in learning beyond school, particularly low achievers. ILT-based learning offers the opportunity for short bursts of learning which can be assessed and recognized through online methods.

There is no doubt that, to date, research programmes on learning with IT post-16 have tended to be short term, and instrumental to decision-making. They have concentrated on speedy implementation of initiatives and supporting development rather than asking fundamental questions. Some current priorities in the sector further illustrate the point: it would be useful to identify in each case more fundamental research questions which need to be asked: the paper returns to these later.

For example, from the current concerns and portfolios of FEDA and Becta and other partners in the NLN initiative, there is work under way looking at how to establish and manage learning centres in the context of much existing practice and many recent national and international developments. This includes the identification of generic models, producing criteria for judging effectiveness, and identifying the contexts in which the centres work best. Analysis of the development of ICT-based learning centres, for example, will produce evidence about the role of technology in learning and the management of such centres.

Tracking learners and learning is particularly important in distributed, distance and open learning environments, to maintain some coherence but also in relation to funding. Part of the technological answer to this is reflected in the current interest in 'managed learning environments' (MLEs) which are defined to include the whole range of information systems and processes of the college that contribute directly or indirectly to learning and learning management. A group established by the Joint Information Systems Committee for Integrated Environments for Learners is producing guidance for purchasers of MLEs.

Having invested heavily in IT equipment, colleges are still struggling with issues relating tc learning materials. The need for digital and multiple media content produces a myriad of questions and concerns about availability, access, use, cataloguing, retrieval and storage, a: well as issues of intellectual property rights and copyright. This can involve partnership: between public and private sectors to create learning materials, or major decisions b! colleges to invest in such capability. There have been a number of important sector-widi initiatives involving the Language Development Network (LDN) and the FE Nationa Consortium (FENC). 
The incorporation of international standards, for example for metadata, in learning and assessment materials and back office systems, has necessitated contact between FE and $\mathrm{HE}$ and with the global IT community. This is a particular area where the decisions of the UfI are having an influence on the sector. Running across all of these is the development and use of Internet and intranet services in colleges, whether reflected in policies for acceptable use or the skills of staff to create and manage Web-based environments and materials. An associated issue is how to recruit and retrain technical staff in what can be a very competitive area of the labour market.

Meanwhile, colleges have all recently been asked to submit approved ILT strategies to secure further involvement in the NLN initiative. As part of this they are deciding how to reconcile and pay back capital investment in IT, how to make further investment decisions, and how to ensure revenue streams for upgrading and updating. This will determine whether the sector and individual institutions are at the leading edge.

Some of these priorities are referred to again below as we examine what this all means for the research agenda.

\section{Does IT work?}

Efficiency and effectiveness have also been at the centre of research concerns. Those responsible for managing institutions and making investments in resources are rightly anxious to have 'harder' information about the return on their investment. It is useful to note here that during Autumn 2000, FEDA will publish a report on the topic based on research undertaken as part of the FERL programme. This examines the outcomes of IT initiatives in a number of sector colleges. And the impact of the NLN initiative itself is being evaluated by FEDA and a team from Sheffield Hallam University (as reported in another paper in this edition).

The particular concern about how and whether IT 'works' has raised fears among the teaching workforce. This is inevitable in any industry when new technologies are introduced; lecturers and others supporting learning are concerned about the impact of IT on their role and even on their livelihood. The lessons of history are both comforting and disturbing. Opportunities for work can be increased by the opportunities in the new economic environments opened up by technology; but it is nearly always different work: change is inevitable.

Research questions that appear to be finance-driven will fuel such concerns. But the big issue implied by such questions is how, not if, the nature of teaching, and the teaching profession, will need to change to meet the demands of new learners and the 'new learning'. We need to explore the development of new approaches, practices and standards for teaching and associated professions, working with FENTO and other standards bodies. Development work is needed to model and track the transformation of the role of teachers as their practice develops to become tutors, facilitators, supporters, coaches, advisers, mentors and, in the language of 'neighbourhood renewal' policies, 'animateurs' of learning. The change may perhaps relate more to skills delivery than to knowledge. There will still be a need for transmitting information and knowledge, including lecturing and instructing. Undoubtedly, however, a new balance of approaches will develop and blur the boundaries between the different professionals engaged in post-16 learning. 
To what extent does technological development itself really affect how we approach the future of post-16 learning - how people learn successfully, with whatever mix of technological and human interaction? At worst, the technology itself can blind us to the real concerns about what is wrong with the education system, the world of work and life patterns for which learning prepares and re-prepares people. IT can be perceived as one of the biggest drivers and instruments in building a better-educated, skilled, creative and innovative workforce and society. The core purpose of research into IT and learning must be systematically to enhance learning, using the best appropriate technologies available. Computers are simply the means to an end, not the end in itself.

In this context, the focus in IT-related research and practice has now strongly shifted to teaching and learning - and the need for ambitious and longitudinal studies to explore the potential of new technologies to enhance the learning process and to engage more people in learning. Learning with technology is seen to be central to debates about how to bring learning closer to people and their real concerns in work and daily life.

\section{The deeper context for research and IT}

It is questionable how far the issues underlying our education system (for example, social divisions, skill levels and competitiveness) will be fundamentally affected specifically by technological environments. However technology has offered a new context in which research can address endemic issues in post-16 learning and ask key questions. Apart from the many human perspectives touched on above and later, these concern, firstly, the way in which institutions and the teaching and educational support professions will need to change and develop if people are using interactive technologies at least as part of their learning. Second is the question of whether IT will help to realize an inclusive learning society, build a more skilled and creative workforce, and change what, how, with whom and where people learn. Thirdly, it is about who makes those choices - the balance between individual learners, communities, global economic forces and the state in determining learning patterns and modes of delivery. Unsurprisingly, the biggest issues are the 'people issues'.

Some current research questions which professionals are asking about technology and learning include:

- Is ICT just useful to motivate and to excite people to engage, that is, to stimulate demand and participation, or does it really support learning? Do people ever learn purely on their own (whether with a screen, book or pen and paper) or is learning always a social process?

- What works for learners? What are the opportunities, and the pitfalls? How do people learn with IT, what works for them and what does not? How can IT help to change the delivery of learning in the interests of learners? How does information, through learning, become knowledge? How will the twenty-first century 'autodidact' really learn?

- Is ICT simply a tool, or can the range of new technologies change fundamentally the way people live and learn? For example, does the availability of information on the Web mean that adult learners may be reluctant to go 'back to basics' when they can follow 
their desires and curiosities - beyond the teacher-rationed materials and curriculum frameworks? Does it mean that people can forego learning, or 'forget'l those basic skills that technology can do for us - calculating number, spelling and grammar, for example - and concentrate on the skills and knowledge they really want? Does it matter if people cannot easily write or draw by hand? Do the new skills replace, change or complement the old ones? What would be the wider implications of such fundamental shifts in human practices, ways of learning and expressing creativity?

- How will effective use of technology for learning change the roles of teachers/tutors/ lecturers/ advice and guidance professions/ trainers/ librarians and learning resource professionals?

- Is the notion of screen-based learning, whether as 100 per cent, or as a major element of the learning process, likely to succeed? Or is learning, as the evidence and history seem to suggest, essentially a social process which leads to the internalization of skills and knowledge by individuals? What is the likely balance?

- What is the impact of technology - including learning technology - on craft, manufacturing and other vocational areas, where things are still physically made, of old and new materials, and how can its potential be exploited in learning? We do not all live on 'thin air' (Leadbeater, 2000; DTI White Paper, 1998; Hughes and Mager, 2000).

- The 'information society' and 'knowledge-driven economy' (twin concepts but whose different emphases are themselves worthy of discussion) will use know-how, information and generic skills with an increasingly adaptable workforce, even in manufacturing and craft and the arts - but how will the relationship change? What do providers of learning need to be doing here to address the impact of new technologies? The focus on information creates myths which obscure the social and economic forces which are also driving change. It also cloaks the realities of economic development and the breadth of the skills base needed at local, national and global levels. Generic (key and basic) skills may be critical and increasingly important, but craft and technician skills will remain important in FE and vocational learning. Research and enquiry are needed to understand the range of vocational and life skills which will be needed in 'post-industrial' Britain.

- What does ILT already, and potentially, do to the way human beings in families, localities and nations communicate and interact for personal, educational, social and economic motives?

- Should the nature of what we call learning, as we strive for a learning society, be altered to include much informal, individual and group learning, for example through the medium of the Internet?

- What are the implications of electronic and mobile learning (e-learning and mlearning) using WAP mobile phone, digital broadcasting and other emerging technologies for learning providers such as colleges and community education centres?

- Access to the technology and to the learning it enables must remain at the centre of learning with IT. The danger of developing IT 'haves' and 'have nots' will remain a concern, including the potential for developing a new 'illiteracy' among the adult 
population. Age and gender are particular concerns. How can we communicate better with disaffected young people and help them back into learning?

- IT raises issues about uncontrolled access to information and communication, reinvigorating debates about censorship and freedom of information, however distasteful. IT can be seen as exacerbating inactivity and loss of drive especially among young people, raising associated health concerns. Computer games merit further investigation here, seen on the one hand as the new threat to learning, thinking and active development and on the other as a major opportunity to exploit, to break down the divide between playing and learning/working.

\section{The value and reality of IT research}

As in most educational research, there is a perceived divide between investigating 'what works' and deeper tunnelling into underlying issues, values and concepts. At the heart of everyone's concerns is the potential of IT to increase access, participation and success for learners. It follows that the learning with IT research agenda needs to integrate both aspects. Equally, research must be directly linked with development activity, improvements in practice and innovation. The two sides must inform each other. This approach is central to FEDA's research effort (Stanton and Morris, 2000).

The post- 16 learning with IT agenda must define terms broadly and clearly. Technology must be an inclusive concept, perhaps remembering the tenets of 'educational technology', where what matters is what works to support effective teaching and learning. So, as well as PCs, Internets and intranets, CDs, laptops and palmtops, satellite and terrestrial TV, mobile phones and landlines, tele- and video conferencing, we should remember pencils and paper, paints, faxes, whiteboards and all the other technologies which refuse to lie down and die. All of these, singly and in combinations, together with the persistent technologies from earlier ages, should be embraced. The agenda should be about multiple media, combinations assembled by providers to suit the needs of learners and users of the education and training system.

We also need research now on how to exploit the newest technologies for learning. The new mobile phones, for example, have real potential to address some of our core concerns about widening participation and social inclusion. With European and UK partners, FEDA is undertaking research into 'm-learning' funded through the EU fifth Framework Information Society Technologies (IST) initiative. The m-learning project's ultimate objective is to develop and prove prototype products and services which will provide information, advice and guidance and portfolios of very small modules of learning by means of technologies which are inexpensive, portable and accessible to the majority of EU citizens. The products and services arising from the project will be designed to support the development and achievement of lifelong learning objectives. The primary target groups of the m-learning project will be young adults who are not currently engaged in education or training; casual, temporary or self-employed adults; and adults in lowpaid/low-skill employment with basic or key skills learning needs.

The 'technology side' of the work will investigate the features offered by existing and forecast mobile devices and communications networks, and their feasibility for 
contributing to lifelong learning. On the 'people side', the work will look at motivation, preferences and behaviour of young adults who currently use mobile phones and handheld electronic games. There is already relevant work relating to children at the University of Tampere in Finland. Our project will collate information and findings from this and other related research in Europe and elsewhere.

As far as learning is concerned, in the post-16 sector the concept is extremely broad and needs to encompass informal as well as formal learning, learning in institutions and learning outside the walls of public providers. Formal learning that leads to qualifications is central, particularly in 16-19 education, whether it is delivered through open, distance and e-learning or by sitting in groups in colleges. However, learning technologies open up huge possibilities for informal learning for specific purposes and interests, for consumers, for leisure interests, for fact-finding, exploring curiosities, reading, writing and relating.

\section{Research, development, innovation}

Finally, what is the parallel development and innovation agenda? The most successful element in the QUILT programme in stimulating culture change and curriculum development was a series of over 100 development projects run in colleges and managed as a national initiative by FEDA. The projects were designed to enable curriculum specialists to help themselves, to explore applications of technology and to tailor projects appropriately to a specific learning environment. The projects also supported (for example) the development of partnerships between providers, a focus on specific curriculum areas, intranet development across colleges and a managed approach to the cascading of good practice at national level. A key benefit was the development of action research skills among practitioners. This is not research with a capital $\mathbf{R}$. It is an example of fieldwork, action research and development to address change.

Partly in recognition of the gains made by the QUILT development initiatives, the National Learning Network (NLN) approach has been adopted in the new phase FE ILT development. The emphasis in the NLN is on innovation: a small number of larger projects - twenty in total - will explore a variety of technologies for teaching and learning. The coverage of the first twelve projects illustrates the sector's awareness of the issues and the extent to which recent years have witnessed major advances in the use of technology. The project details can be seen on the NLN website, where all the project reports will eventually be available.

\section{Conclusion}

The FEFC's ILT committee (FEILTC), chaired by Jenny Scribbins, Principal of South Thames College, has overseen research in ILT in the FE sector. The committee brings together expert bodies, principals and senior managers and national organizations across the UK. The committee's work has helped the sector to tackle fragmentation and support coherence. There has been close contact with the HE research community, JISC and UKERNA, and the IT industry. It will be important to develop a coherent approach and an overview of research in learning with IT across the new Learning and Skills sector. FEDA has a new role and remit as the organization appointed to lead the development of research capacity in colleges, in addition to work-based and community learning. FEDA will be working with others to establish a much stronger research base for the future. This 
will involve partnerships across the sector, with $\mathrm{HE}$ and others in the research community; there will be a strong emphasis on networks, including e-networks, and databases to build more coherence into our research efforts. The aim is to help FEDA to improve knowledge, support creativity and innovation, and cascade good practice. Learning with IT will remain a top priority. It is a challenging agenda.

\section{Note}

'My thanks to Tim O'Shea who introduced me to Roland Barthes' concept of 'forgetting'.

\section{References}

Department of Trade and Industry (1998), Building the Knowledge Driven Economy, DTI White Paper, December.

Hughes, M., and Mager, C. (2000), The Skills Agenda - Issues for Post-16 Providers, London: Further Education Development Agency.

Leadbeater, C. (2000), Living on Thin Air, London: Penguin.

National Learning Network (2000), College Case Study, National Learning Network Evaluation Report, May.

O'Shea, T. (2000), Guardian, 18 April.

Seely Brown, J., and Duiguid, P. (2000), The Social Life of Information, Harvard Business School Press.

Stanton, G., and Morris, A. (2000), 'Making R \& D more than research plus development', Higher Education Quarterly, 54 (2), 127-46. 